\title{
Psychological Aspects of Pedagogical Communication
}

\section{Meruyert Assilkhanova}

Flat 33, Kozhamkulov street 157, Almaty, 050026, Kazakhstan

Email:m.assilkhanova@mail.ru

\section{Saltanat Tazhbayeva}

Abay Kazakh National Pedagogical University, Almaty, Kazakhstan

Lyazzat llimkhanova

Abay Kazakh National Pedagogical University, Almaty, Kazakhstan

\section{Doi:10.5901/mjss.2014.v5n20p2726}

\begin{abstract}
This study analyzes pedagogical communication, a specific aspect of a teacher's practical work in real time. It includes specific content and comprises methods of interaction between pedagogical participants, the subject areas, and cognition of communication, i.e., the basic characteristics of communication. Based on this understanding, pedagogical communication can be considered as a factor that optimizes the educational process.
\end{abstract}

Keywords: professional, factor, phenomenon, specifics, communication, function, coordination, self-expression, syndicated, presentation, translational, cognition, initiator, structure

\section{Introduction}

Pedagogical work is a profession in which communication plays a central role. It is the primary tool through which education and upbringing are implemented. Pedagogical communication was identified as a scientific category in the mid1970s.

The study of pedagogical communication was initiated by several different lines of research, such as that related to social perception problems (Bodalev), collective theory and interpersonal relationships in the pedagogical process (Kolominskiy, Petrovskiy), and the psychology involved in teaching (Kuzmina, Sherbakov) (Brudniy, 1989). These psychological studies laid the groundwork for the initial research on issues related to pedagogical communication.

In psychology, pedagogical communication is described as a special type of communication (in comparison with business or professional communication between a doctor and patient, etc.) that contains inherent features specific to interaction in education. The understanding of pedagogical communication is based on principles which state that communication holds an independent place among the most important types of human activity (Anan'ev), influences personality formation (Anan'ev), is multifunctional (Anan'ev, Bodalev, Lomov, Myasishev), and is the most important medium through which relationships are maintained (Myashishev). This process involves important internal aspects of human interaction, participants learning to communicate with each other (Anan'ev, Bodalev), and social-perceptual processes that are crucial for the qualitative development of personality (Bodalev, Kondrat'eva). Zimnyaya (2000) examines pedagogical communication as a form of educational interaction that involves cooperation between teachers and students, that is, personally and socially oriented interaction.

\section{Methods}

According to Kan-Kalik and Kovalev (1987), professional pedagogical communication is a system of techniques and methods that ensures the realization of the goals and objectives of pedagogical activity as well as of individuals involved in organizing this activity and guiding the social-psychological interaction between teachers and learners. To ensure learning, this interaction includes information exchange, interpersonal cognition, and the organization and regulation of relationships through various means of communication. The process of pedagogical communication includes the 
integrated pedagogical self-presentation of the teacher's personality to his/her audience. The teacher organizes and takes control of the process, thus serving as a catalyst for it (Kan-Kalik \& Kovalev, 1987). Slastenin and Mazher (1991) describe pedagogical communication as a multifunctional process comprising the organization, establishment, and development of communication, understanding, cooperation, and interaction between teachers and students, generated by the objectives and content of their mutual activity. Leont'ev (1979) emphasizes the importance of creating a favorable psychological climate for pedagogical communication and offered the following definition of this phenomenon: "Pedagogical communication is a type of professional communication between teachers and students in the classroom during the lesson or outside it as part of upbringing that serves a pedagogical function, and it is directed (if complete and optimal) toward creating a favorable psychological climate as well as enabling psychological optimization of educational activity and relationships between teachers and students within the class."

\section{Results and Discussion}

Thus, researchers, while defining the essence of pedagogical communication, rely on the following fundamental position related to the analysis of this phenomenon: (1) pedagogical communication should be studied within the framework of a general theory of communication and should employ the same terms; (2) during the analysis, the specifics of pedagogical communication must be considered; and (3) pedagogical communication is a form of educational interaction that involves cooperation between teachers and students.

According to Zimnyaya (2000), the specifics of this form of interaction lie within its polyobjectional and polysubjectional orientations. The polyobjectional orientation of pedagogical communication is concerned with the fact that it is directed not only toward the teacher's actual interaction with learners but also toward the teacher's organizing the educational material and creating the foundation for this creativity. This provides the basis for the pedagogical system. The researcher highlights a threefold orientation of communication, focusing on the educational interaction itself, the students (their present state and future development), and the learning material.

As a form of educational cooperation, pedagogical communication is characterized by a threefold orientation of its subjects: personal, social, and subjectional. Therefore, the peculiarity of pedagogical communication is reflected in its organic combination of elements of personally, socially, and subjectionally oriented communication as well as in the implementation of its functions, which are related to the teacher's goals. According to Brudniy (1989), communication serves four main functions: (1) instrumental-coordinating activities; (2) syndicative-creating communities and groups; (3) self-expressive-presenting one's personality; and (4) translational.

The researcher believes that the latter function is of particular interest, because it is the basis of learning; education occurs through communication. Kaprenko proposed to classify the functions of communication and its results into the following categories: contactive, informational, incentive, coordinational, function of understanding, emotive function of establishing relationships, and function of influence. Examining pedagogical communication, Zimnyaya (2000) emphasizes the presence of three functions within this process: education (as a manifestation of the translational function), upbringing, and facilitation (the function of facilitating communication). Lobanov notes that professional pedagogical communication had distinctive functions. Therefore, along with the information, education, and contact functions, the researcher highlights the following functions: (1) enhancing mutual relationships; (2) organizing and implementing activities; (3) familiarizing a partner with an experience and the values of communication with the initiator of that experience; (4) facilitating the child's communication; (5) participation; and (6) developing the student's personality.

Thus, there are several approaches to determine the functions of pedagogical communication, even though many studies underline its multifunctionality. The broad scope of these functions allows us to solve important problems related to education and upbringing.

The question of the structural unit of pedagogical communication has been addressed differently in various studies. Several researchers (Kan-Kalik \& Kovalev, 1987; Lisina, 1997; Zimnyaya, 2000) argue that the structural unit of pedagogical communication is a communicative task that operates within the communicative act. Kan-Kalik and Kovalev (1987) state that while building a communicative task, it is necessary to consider the presuppositions: the pedagogical problem, the current level of pedagogical communication between teachers and students, the individual characteristics of teachers and students, and the record of work methods (Slastenin \& Mazher, 1991).

Communicative tasks represent a problematic communication situation that must be resolved to ensure efficient methods of pedagogical influence in a suitable context within a professional pedagogical communication situation. The researcher proposes to schematically express this system of professional pedagogical communication through the following : (1) a pedagogical task; (2) a system of selected education and upbringing methods to solve the task; (3) a system of communicative tasks that must be solved to implement education and upbringing methods chosen by the 
teacher; and (4) pedagogical influence.

Lisina (1997) argues that the purpose of the communicative task is to achieve a situation in which participants take various actions in a process of communication. The communicative task depends upon internal and external conditions, but more precisely, it characterizes the communicative activity. The communicative task, which drives verbal and nonverbal responses, is a productive and receptive unit.

From a teacher's perspective, the following groups of communicative tasks are relevant in pedagogical communication: (1) transmission of information; (2) request for information; (3) motivation for verbal or non-verbal action; and (4) expression of opinion regarding verbal and non-verbal action of the partner in pedagogical communication.

Several studies have attempted to categorize communicative tasks. However, the communicative tasks of speech are generally highlighted: message, persuasion, motivation, inducement, approval, explanation, proof, etc.

Kluyeva et al. (2003), Batrakova, and Varenova believe that the structural unit of pedagogical communication is a situation, which represents a specific aspect of a teacher's practical work in real time. It contains specific content and comprises the forms of interaction among the situation participants, the subject area, and cognition of communication, i.e., the basic characteristics of communication (Kluyeva et al., 2003).

\section{Conclusion}

Researchers have adopted different approaches to the pedagogical communication problem; however, they have not arrived at a consensus regarding the content, structural unit, and functions of pedagogical communication. Nevertheless, these studies reflect essential aspects related to understanding the problem. A survey of teachers with different levels of experience suggested that many teachers are unaware of the objectives and functions of pedagogical communication; some neither understand the structure nor perceive the communicative task as necessary in the educational process.

All human activities include communication, but in pedagogy, it is an instrument of influence and is professionally significant. This view is shared by Dobrovich, who believes that "no matter what subject is taught by a teacher, above all, he teaches to a belief in the power of the human mind, a powerful need for knowledge, the love of truth, and a dedication to community service." Leont'ev (1979) notes the importance of influence in pedagogical communication. He states that the optimal pedagogical communication "creates the most favorable conditions for the development of students' motivation, the creative nature of educational activity, and the pupil's personality; provides a favorable emotional climate for education (in particular, prevents the emergence of a "mental barrier"); enables the management of socialpsychological processes in a classroom; and most effectively uses the teacher's personality.

Therefore, an effectively organized process of pedagogical communication aims to (1) provide real psychological contact between teachers and students, making them subjects of communication; (2) overcome various psychological barriers that arise during student-teacher interaction; (3) encourage students to shift from their usual position of being led to that of independently participating in teamwork, consequently transforming them into subjects of pedagogical creativity; and (4) create productive interpersonal relationships between teachers and students that combine professional and personal levels of communication which are integrated with the social-psychological structure of the educational process.

Based on this understanding of pedagogical communication, it can be considered as a factor that optimizes the educational process.

\section{References}

Brudniy, A. A. (1989). Understanding of communication. Moscow.

Kan-Kalik, V. A., \& Kovalev, A. G. (1987). Classification of psychological types of communication. Problems of psychology, 3 ,

Kluyeva, N. V. et al. (2003). Pedagogical psychology: Textbook for students of higher educational institutions. Under supervision of N.V. Kluyeva. Moscow.

Leont'ev, A. A. (1979). Pedagogical communication. Moscow.

Lisina, M. I. (1997). Communication, personality, and psychology of children. Under supervision of A. G. Ruzskaya. Moscow.

Slastenin, V. A., \& Mazher, N. E. (1991). Diagnostics of professional competence of young people to pedagogical activity. Moscow.

Zimnyaya, I. A. (2000). Pedagogical psychology. Textbook for higher educational institutions. Moscow. 